\author{
Путра В. А. \\ V. A. Putra \\ РЕПРЕЗЕНТАЦИЯ ЭДИПОВА КОМПЛЕКСА \\ В ОБРАЗЕ ГАРРИ ПОТТЕРА: ОПЫТ ПСИХОАНАЛИЗА
}

\title{
OEDIPUS COMPLEX REPRESENTATION \\ IN THE IMAGE OF HARRY POTTER: EXPERIENCE OF PSYCHOANALYSIS
}

Путра Виолетта Анатольевна - преподаватель кафедры хореографии Крымского университета культуры, искусств и туризма (Россия, Симферополь); 295017, Республика Крым, г. Симферополь, ул. Киевская, 39; тел.: + 7 (3652) 27-64-58. E-mail: Profi-vita.75@bigmir.net.

Mrs. Violetta A. Putra - lecturer of the Department of Choreography, Crimean University of Culture, Arts and Tourism (Russia, Simferopol); 295017, Republic of Crimea, Simferopol, 39 Kievskaya str.; tel.: + 7 (3652) 27-6458. E-mail: Profi-vita.75@bigmir.net.

Аннотация. Общие методики применения ключевых психоаналитических методов по отношению к истории, культуре, литературе, науке, религии разрабатывались 3. Фрейдом в рамках «прикладного психоанализа». Приближенность психоаналитической методики исследования к методам литературоведения стала условием формирования «психоаналитического литературоведения», или «литературоведческого психоанализа» в отечественном и западном научном поле ХX столетия. Представляется перспективным применение психоаналитической методологии к анализу современных литературных текстов, например, написанной Дж. Роулинг на рубеже XX-XXI вв. серии романов о Гарри Поттере, породившей обширную академическую литературу, в том числе психоаналитическую, так называемую Potteriana psychological. Основное внимание привлекает ярко выраженная репрезентация эдипова комплекса в художественном образе главного героя. Эффективность применения методологии психоанализа в области исследований художественных экспериментов и течений в искусстве XX-XXI вв. не вызывает сомнения.

Summary. General methods of application of basic psychoanalytic methods in relation to history, culture, literature, science, and religion were developed by S. Freud in the «applied psychoanalysis». Proximity of the psychoanalytic methods of research to the methods of literary studies became a condition for the formation of «psychoanalytic literary criticism», or «literary psychoanalysis» in the Russian and Western academic field of the 20th century. It seems promising to apply psychoanalytic methodology to the analysis of modern literary texts, for example, written by J. Rowling at the turn of the 20th and 21 st centuries a series of novels about Harry Potter, which gave rise to extensive academic literature, including psychoanalytic, the so-called «Potteriana psychological». The main attention is attracted by the pronounced representation of the Oedipus complex in the artistic image of the protagonist. Effectiveness of applying the methodology of psychoanalysis in the field of research of artistic experiments and trends in the art of the 20-21 centuries cannot be doubted.

Ключевые слова: 3. Фрейд, психоанализ, эдипов комплекс, литература, Дж. Роулинг, Г. Поттер.

Key words: S. Freud, psychoanalysis, oedipus complex, literature, J. Rowling, H. Potter.

УДК 159.964.2:821.111

Статья продолжает ряд публикаций автора, посвящённый изучению роли психоанализа в развитии современной культуры [5; 6].

Существуют многочисленные «совпадения» между сферами, с которыми имеют дело литература и психоанализ. Последний нередко определяют как talking cure (в переводе с английского - «лечение разговором»); действительно, речь - как терапевта, так и пациента, в процессе психоаналитической терапии имеет основополагающее значение. В некотором смысле сеансы психоаналитической терапии представляют собой восстановление той роли, которую слово должно играть в человеческой жизни. 


\section{Учёные записки}

Комсомольского-на-Амуре государственного технического университета

Психоаналитический дискурс включает элементы, привычно воспринимаемые как литературные и (или) поэтические, в том числе, например, метафоры, которые 3. Фрейд особенно глубоко исследует в своей работе «Толкование сновидений». Следуя подходу Фрейда, Ж. Лакан также признаёт основополагающее значение метафоры для деятельности человеческой психики.

Психоанализ имеет дело с интерпретацией, в основе его подхода лежит идея о существовании некоторых замаскированных мотивов и значений, которые «работают» через другие значения. Психоанализ призван открывать природу субъекта: кем является тот, кто переживает тот или иной опыт, что представляет собой этот опыт в рамках психических и культурных сил, которые определяют многое в нашем существовании.

Психоанализ исследует связь личных тревог, страхов, желаний и других жизненно важных для нас эмоций с общекультурной ситуацией наших социумов. При этом культура рассматривается как важный источник информации о психической жизни индивида [12].

Связи психоанализа с литературой специально посвятил словарную статью Б. Д. Карвасарский, который писал: «Многие ключевые понятия философии Фрейда имеют литературное и литературоведческое происхождение. В его произведениях обширно представлены ссылки на Аристотеля, Гёте, Грильпарцера, Гейне, Гофмана, Келлера, Ибсена, К. Ф. Мейера, Ницше, Шопенгауэра, Шекспира, Софокла, Стриндберга, Золя и т. д. В своих исследованиях душевных процессов Фрейд вплотную подошёл к границам естественнонаучных методов, но, в отличие от многих, не остановился на достигнутом и не стал поспешно объявлять несостоятельным всё, что не поддавалось естественнонаучному объяснению. В этом сложном положении он принял неожиданное решение и всю свою дальнейшую жизнь следовал "окольным путём” - путём психотерапевтической реконструкции биографии отдельного человека. В своё время Фрейд заметил, что истории болезни, которые он пишет, читаются как новеллы. В начале века представители гуманитарных наук не мыслили психоанализ вне литературы, к которой психоаналитики обращались в поисках аргументов в пользу своих гипотез. Аналитик и поэт представлялись в известном смысле “коллегами”» [3].

В настоящее время психоанализ как в отечественном, так и в западном литературоведении особенно, считается одним из наиболее адекватных и востребованных методов анализа литературно-художественного текста; сложилось даже направление, так и называемое «психоаналитическое литературоведение», или «литературоведческий психоанализ». Такое положение обусловлено именно значительной приближенностью психоаналитической методики исследования к давно апробированным методам литературоведения: «Он (психоанализ), пожалуй, больше других заслуживает подробного изучения специфики функционирования и особенностей самой методики исследования. Посредством утверждения теоретических концепций, проверенных и описанных в психоаналитических исследованиях, исследователи литературы имеют возможность отыскать внутренние побуждения автора к созданию художественного текста и определённой системы образов, что ему присуща. Ведь художественный текст - явление синтетическое. Он является результатом творческой деятельности писателя, синтезирует и даёт понять переход идеального в материальное, общего в частное, бессознательного в сознательное, внутреннего во внешнее. То есть художественный текст как литературоведческая категория имеет в своей основе такие характеристики, которые не могли оставаться вне поля зрения психоаналитиков» [9].

Подобный подход был заложен самим 3. Фрейдом в рамках так называемого «прикладного психоанализа», целью которого было применение ключевых психоаналитических методов по отношению к материалу, выходящему за рамки собственно психологических и (или) психиатрических исследований, - истории, культуре, литературе, науке, религии и т. п. Фрейд активно разрабатывает общие методики подобных подходов в таких работах, как «Бред и сны в "Градиве" В. Йенсена», «Леонардо да Винчи. Воспоминание детства», «Достоевский и отцеубийство», «Тотем и табу», «Человек Моисей и монотеистическая религия» и др.

Несомненную близость художественной литературы и психоаналитической традиции (в первую очередь представляемой им традиции аналитической психологии) по многим 
основополагающим позициям отмечал также и Карл Густав Юнг: «Эти отношения основываются на том факте, что конкретное занятие искусством является психологической деятельностью и, поскольку оно является таковой, оно может и должно быть подвергнуто психологическому рассмотрению, потому что под этим углом зрения оно, как и любая вытекающая из психологических мотивов человеческая деятельность, является объектом психологии. Это положение, однако, очень чётко определяет рамки приложения психологической точки зрения к искусству: предметом психологии может быть только та часть искусства, которая представляет собой процесс художественного созидания, в противоположность другой, составляющей собственно сущность искусства. Это вторая часть, то есть то, что стоит за вопросом, чем является искусство как таковое, - предмет исключительно эстетико-художественного рассмотрения, но отнюдь не психологического» [10].

Художественную литературу К. Г. Юнг представляет как один из возможных вариантов «воплощения» общечеловеческих архетипов, как «высшую форму выражения глубин всеобщего духа». Однако не всякое литературное произведение является по своей природе «архетипичным», то есть выражающим архетипы, - а значит, не всякое литературное произведение является «приобщённым к общечеловеческому бессознательному». Этот коллективный опыт может отразить в своих произведениях только такой писатель, который способен, как любил выражаться сам Юнг, «слышать голос глубин», - поскольку он «фиксирует не только свой сознательно осмысленный опыт (как писатель психологического типа), но и воссоздаёт в тексте страхи, сны, предчувствия, восходящие к коллективной психологии... Вне рациональной установки автора архетипическую инструментовку могут получить сюжет, мотив, образ, деталь. В этом случае базовым будет архетипический смысл, на который налагаются более поздние напластования мифологические, религиозные, научные, индивидуальные... Основной целью анализа литературного текста становится выявление индивидуально-авторской специфики архетипа $[2,17]$.

Психоанализ оказал сильное влияние на формирование и развитие модернизма и постмодернизма - «визитной карточки» всей культуры и, в частности, литературы ХХ столетия. Советский и российский философ и культуролог Н. С. Автономова говорит о развитии модернистской и постмодернистской литературы как «особой культуры обращения со словом, чувствительной к открытиям психоанализа» [1, 441].

С одной стороны, это течение, как и подход 3. Фрейда, буквально пронизывает неприятие современной культуры, её сковывающих индивидуальность ограничений. «Модернизм... был экспериментален по стилю и приёмам; по сути же он был протестом против массового общества и присущего ему конформизма, вызовом гениев - одиночек жизни...» [4, 597].

Однако в качестве ещё более важной характеристики данного направления исследователи называют смену внутренних парадигм, в корне меняющую общий смысл произведений: «у реалистов психологизм, у модернистов психоанализ; у реалистов в основе образа индивидуальность, у модернистов - индивидуализм...» [7, 450].

Представляется перспективным применение психоаналитической методологии к анализу современных литературных текстов. Так, серия романов о Гарри Поттере, написанная Дж. Роулинг на рубеже XX-XXI вв., породила обширную академическую литературу, в том числе психоаналитическую, которую называют Potteriana psychological - «Психологическая Поттериана». Исследователей интересуют разнообразные психоаналитические характеристики эпопеи, однако основное их внимание сосредоточено на ярко выраженном в сюжетной линии «эдиповом» материале $[11 ; 13]$.

Мы обнаруживаем фрейдистскую так называемую «первичную сцену» - инфантильную травму - в воспоминаниях Гарри о том эпизоде его детства, когда Волдеморт явился в дом Поттеров и попытался убить его. Здесь Волдеморт выступает как образ «отца-соперника» Гарри, отделяя его навсегда от матери, и он действительно, как это свойственно образам и проекциям, остаётся «в голове» Гарри на протяжении большей части эпопеи. Поскольку наше сознательное эго обычно отказывается воспринимать родного отца как нечто враждебное, Гарри узнаёт, что когда-то у него был прекрасный отец (Джеймс), убитый тем самым Волдемортом, который хотел 
убить и самого Гарри. Во многих сказках присутствует этот мотив: идеальная (идеализированная, сказал бы психолог) мать умирает и заменяется злой мачехой. Фрейд называет этот процесс «расщеплением Я».

К. Ноэль-Смит пишет: «Учитывая, что каждый ребёнок, согласно Фрейду, время от времени фантазирует о том, как избавиться от “конкуренции” одного из родителей посредством его смерти, чтобы насладиться исключительным “обладанием” вторым родителем, - читатель "Гарри Поттера" может увидеть в тексте исполнение самых затаённых собственных фантазий, однако без горя и без стыда, которые обычно сопровождают эти бессознательные фантазии при их случайном проникновении в сознание: ведь мы знаем, на сознательном уровне, что это на самом деле не так; бессознательно же смерть родителей Гарри представляет собой впечатляющее исполнение эдиповых фантазий» [11].

С этих позиций мы имеем здесь классический пример эдипова комплекса - один в один с тем, как описывал его сам Фрейд, в частности, в работе «Анализ фобии пятилетнего мальчика»: «В своих отношениях к отцу и матери Ганс самым ярким образом подтверждает всё то, что я в своих работах "Толкование сновидений" и “Три очерка по теории сексуальности" говорил о сексуальных отношениях детей к родителям. Он действительно маленький Эдип, который хотел бы “устранить" отца, чтобы остаться самому с красивой матерью, спать с ней... Исходящий из этого желания смерти отца и, следовательно, нормально мотивированный страх перед ним образовал самое большое препятствие для анализа, пока оно не было устранено...» [8].

В более позднем возрасте, в котором мы встречаем Гарри, у него есть фактический отец, имя которого - Вернон Дарсли. Гарри видит Вернона в том же критическом ракурсе, в каком многие подростки видят своих отцов: возможно, «реальный» Дарсли показался бы нам совсем не таким отвратительным (правда, тут фантазия ребёнка подкрепляется авторитетом автора книги: мы ведь читаем не описание фантазий Гарри, а его «реальную» историю). С этого пункта начинается процесс, который Юнг называет «индивидуацией» - обретением собственной индивидуальности. Перед нами есть и пример неудачной индивидуации - Дадли, кузен Гарри. Если Гарри не хочет превратиться в избалованного и инфантильного Дадли, ему предстоит успешно пройти испытания, стоящие между ним и взрослой жизнью. Этот процесс происходит в Хогвартсе, но в конце концов Гарри должен покинуть даже Хогвартс и показать, что он может справиться с проблемами взрослой жизни.

Идентифицировавшись с отцом и (или) с другими персонажами, играющими в романах роль «заместителей» отца Гарри, он, наконец, обретает уверенность в себе и завоёвывает новых друзей. Для этого он, в частности, должен деидеализировать не только отца и Дамблдора, но и их противника - тёмного лорда Волдеморта (инфантильное восприятие которого включало то, что можно назвать «негативной идеализацией», то есть переоценку мощи и силы Волдеморта и страх перед ним), образ которого таким образом становится более человечным, понятным и в долгосрочной перспективе, вероятно, не таким пугающим [13].

Список значимых фигур в жизни Гарри, в которых можно видеть «заместителей» отца, достаточно обширен. Некоторые из них выступают как доброжелательные проводники и помощники (Альбус Дамблдор, Сириус Блэк, который и впрямь является крёстным отцом Гарри; Люпин, мистер Уизли), существует ещё и Северус Снэйп - строгий педант, который, как кажется Гарри, враждебен ему, что в итоге оказывается иллюзией. Напротив, Снэйп во многом даже более эмоционально относится к Гарри, чем даже профессор Дамблдор. Знаком постепенного взросления Гарри становится то, что он уже не воспринимает их образы в категориях крайностей: как идеальный (Джеймс) или злодейский (Снэйп). В символическом смысле оба сливаются в одно лицо, которых объединяет любовь к матери Гарри, хотя в реальной жизни эта любовь, напротив, заставила обоих относиться друг к другу враждебно.

Драматичность отношений «отец-сын» получает наиболее выпуклое отображение в сценах, где Гарри «противостоит» Волдеморту и... Дамблдору (кавычки здесь потому, что противостояние Дамблдору, конечно, скорее, символично: Гарри не борется с профессором, однако утрачивает часть своих иллюзий относительно него). Символично здесь и то, что Гарри 
обретает свою истинную силу только тогда, когда Дамблдор покидает сцену, якобы предательски убитый «плохим отцом Гарри» (Снэйпом). И этой иллюзии тоже предстоит быть развеянной: мнимое предательство Снэйпа окажется, по сути, подвигом, а сам Снэйп - защитником Гарри и истинным героем. Не случайно в конце седьмой книги мы узнаём, что Гарри дал собственному сыну имена своих «отцов» - Дамблдора и Снэйпа (сына Гарри зовут Альбус Северус Поттер).

Все эти персонажи, включая и Волдеморта, являются символическими версиями фактического отца Гарри. Мы сознаём, что действительно повзрослели, когда видим наших отцов, как они существуют «сами по себе», а не как проекции внутренних драм нашего взросления. Хотя, наверное, мы никогда не сможем добиться абсолютной ясности в этом вопросе, как никогда не достигнем и абсолютной зрелости. Но это цель, к которой стоит стремиться...

В результате исследования сделаем вывод об эффективности использования психоаналитических методов интерпретации литературного текста. Методология психоанализа может найти применение в области исследований художественных экспериментов и течений в искусстве XX-XXI вв.

\section{ЛИТЕРАТУРА}

1. Автономова, Н. С. Познание и перевод: опыты философии языка / Н. С. Автономова. - М.: РОССПЭН, 2008. $-704 \mathrm{c}$.

2. Золотухина, О. Б. Психологизм в литературе: пособие / О. Б. Золотухина. - Гродно: ГрГУ, 2009. - 178 с.

3. Карвасарский, Б. Д. Психотерапевтическая энциклопедия [Электронный ресурс] / Б. Д. Карвасарский.

Режим доступа: http://www.samomudr.ru/d2/Enciklopedija_PSIXOTERAPEVT.pdf (дата обращения: 15.01.2019).

4. Кейзин, А. Мудрость, обретённая в изгнании. Классик без ретуши: литературный мир о творчестве Владимира Набокова: критич. отзывы, эссе, пародии / А. Кейзин; пер. с англ. Н. Казаковой. - М.: Новое лит. обозрение, 2000. - С. 596-599.

5. Путра, В. А. Механизмы символообразования в психоанализе 3. Фрейда / В. А. Путра, О. Б. Элькан // Вестник Московского государственного университета культуры. - 2016. - № 4(72). - С. 59-64.

6. Путра, В. А. Формирование символической сферы культуры в представлениях аналитической психологии К. Г. Юнга / В. А. Путра, О. Б. Элькан // Культурная жизнь Юга России. - 2017. - № 3(66). - С. 20-24.

7. Современные проблемы реализма и модернизм: сб. статей; отв. ред. А. С. Мясников. - М.: Наука, 1965. $615 \mathrm{c}$.

8. Фрейд, 3. Анализ фобии пятилетнего мальчика. Психология бессознательного / 3. Фрейд. - М.: Просвещение, 1990. - С. 39-121.

9. Шевченко, Н. И. Психоанализ как основа методологии изучения литературы / Н. И. Шевченко // Молодой учёный. - 2015. - № 3. - С. 995-996.

10. Юнг, К. Г. Об отношении аналитической психологии к произведениям художественной литературы. Классический психоанализ и художественная литература: хрестоматия / К. Г. Юнг. - СПб.: Питер, 2002. C. $106-130$.

11. Noel-Smith, K. Harry Potter's Oedipal Issues / K. Noel-Smith // Psychoanalytic Studies. - 2001. - Vol. 3.2. P. 199-207.

12. Psychoanalysis and literature [Электронный pecypc]. - Режим доступа: https://brocku.ca/english/courses/4F70/psychlit.php (дата обращения: 15.01.2019).

13. Subkowski, P. Harry Potter - das Trauma als Motor der psychischen Entwicklung / P. Subkowski // Praxis der Kinderpsychologie und Kinderpsychiatrie. - 2004. - Vol. 53(10). - P. 738-753. 